\title{
Fault parameters of the 1896 Sanriku tsunami earthquake estimated from tsunami numerical modeling
}

\author{
Yuichiro Tanioka \\ Dept. of Geological Science, University of Michigan, Ann Arbor
}

Kenji Satake

Seismotectonics Section, Geological Survey of Japan, Tsukuba

\begin{abstract}
The June 15, 1896 Sanriku earthquake generated devastating tsunamis with the maximum run-up of $25 \mathrm{~m}$ and caused the worst tsunami disaster in the history of Japan, despite its moderate surface wave magnitude $\left(M_{s}=7.2\right)$ and weak seismic intensity. This is a typical tsunami earthquake, which generates anomalously larger tsunamis than expected from its seismic waves. Previously proposed mechanisms of tsunami earthquakes include submarine slumping and slow rupture in the accretionary wedge or in the subducted sediments. In this paper, we estimate the fault parameters of the 1896 tsunami earthquake by numerically computing the tsunami and comparing the waveforms with those recorded at three tide gauge stations in Japan. The result indicates that the tsunami source is very close to the Japan trench and the fault strike is parallel to the trench axis. The fault width is about $50 \mathrm{~km}$, suggesting that the tsunami earthquake is a slow rupture in the subducted sediments beneath the accretionary wedge.
\end{abstract}

\section{Introduction}

On June 15, 1896, a very unusual earthquake occurred off the coast of Sanriku, Japan; the ground shaking was relatively weak, but the following tsunami was devastating. A modern estimate [Utsu, 1979] of the origin time and epicenter is $10 \mathrm{~h} 32 \mathrm{~m}$ (GMT) and $39.5^{\circ} \mathrm{N}, 144^{\circ} \mathrm{E}$, respectively. Abe [1994] recently assigned the surface wave magnitude as $M_{s}=7.2$. The tsunami magnitude $\mathrm{M}_{\mathrm{t}}$ was determined as 8.6 from global data $[A b e, 1979]$ and 8.2 from local data [Abe, 1981]. The large discrepancy between $M_{t}$ and $M_{s}$ (Fig. 1) categorizes this event as a typical tsunami earthquake [Kanamori, 1972], which generates abnormally larger tsunamis than expected from its seismic waves.

The unusual nature of this earthquake is more evident when it is compared with the recent 1994 Dec. 28 Sanriku earthquake which generated a small tsunami as expected from seismic waves [e.g., Tanioka et al., 1996a] (Fig. 2). The epicenters of both events are close (less than $100 \mathrm{~km}$ away), and the surface wave magnitudes are similar $\left(M_{S}=7.2\right.$ for the 1896 event while $M_{s}=7.5$ for the 1994 event). For the 1994 event, the maximum seismic intensity was 6 on the Japan Meteorological Agency (JMA) scale, which corresponds to IX on the Modified Mercalli (MM) scale, and many houses along the Sanriku coast were damaged by the shaking. The observed tsunami heights were less than $1 \mathrm{~m}$ and

Copyright 1996 by the American Geophysical Union.

Paper number 96GL01479

0094-8534/96/96GL-01479\$05.00 caused no damage. On the other hand, the seismic intensity along the Sanriku coast from the 1896 event was much smaller, only 23 (weak shaking) on the modern JMA scale corresponding to IV or $\mathrm{V}$ on the MM scale. However, the maximum tsunami run-up height was $25 \mathrm{~m}$ and caused about 22,000 casualties.

Why was the 1896 tsunami so large for its relatively small $M_{S}$ and seismic intensity? Kanamori [1972] indicated that the large discrepancy between seismic and tsunami waves is explained by a slow and long rupture process. Okal [1988], using the normalmode theory, showed that an earthquake source in a shallow sedimentary layer excites much larger tsunamis than in solid rock. Fukao [1979] and Palayo and Wiens [1992] studied other tsunami earthquakes using seismic wave analysis and concluded that tsunami earthquakes are slow thrust events in the accretionary wedge. Satake [1994] modeled the recent 1992 Nicaragua tsunami earthquake and concluded that a slow rupture on a shallow fault in the subducted sediments is responsible for

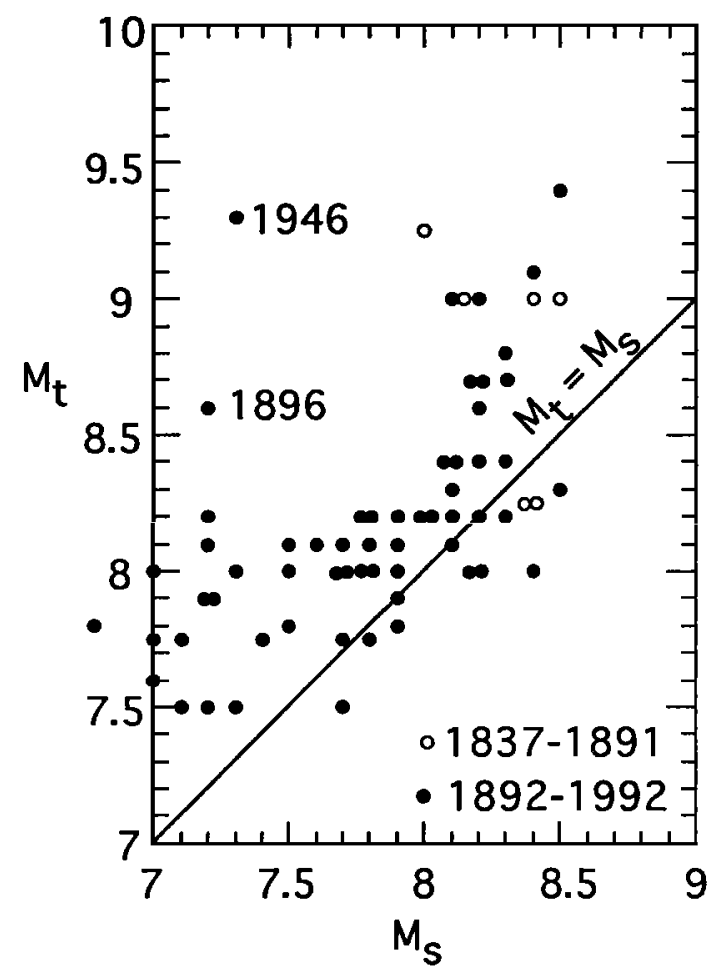

Figure 1. Relation between $M_{t}$ (tsunami magnitude) and $M_{s}$ (surface wave magnitude). The original figure by $A b e$ [1979] is updated by adding recent data and by replacing the $\mathrm{M}_{\mathbf{S}}$ values with more recent estimates [e.g., Abe, 1994]. 


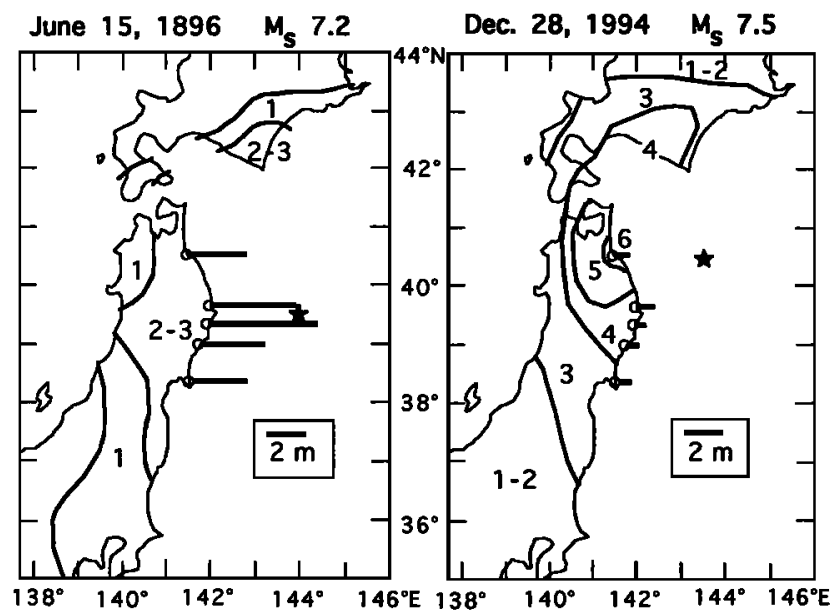

Figure 2. Comparison of seismic intensity and tsunami heights from the 1896 (left) and 1994 (right) Sanriku earthquakes. The stars show the epicenters. The contours represent the seismic intensity distribution on the Japan Meteorological Agency (JMA) scale. The bars show the tsunami heights at five locations (Hachinohe, Miyako, Kamaishi, Oofunato, and Ayukawa from north to south). They are run-up heights for the 1896 event [Iki, 1897] and the amplitudes on tide gauges for the 1994 event.

the large tsunami, as originally suggested by Kanamori and Kikuchi [1993].

In this paper, we make numerical computations of the 1896 tsunami and compare the waveforms with the observed tsunami records to determine the fault parameters. If the 1896 earthquake was a slow rupture in the sediments near the trench, the fault slip should be concentrated near the trench axis. The seismic data from the 1896 earthquake are very limited and it is impossible to resolve the slip distribution. On the other hand, the tsunami waveforms were recorded at several tide gauge stations in Japan.

\section{Data and Method}

Immediately after the 1896 disaster, Iki [1897] surveyed on the Sanriku coast and reported the run-up heights as large as $25 \mathrm{~m}$. The tsunami arrival was visually observed at Miyako meteorological observatory, where instrumental seismological observations were being made [Omori and Hirata, 1899]. The official report in the annual report of the Central Meteorological Observatory states that a weak shock was first felt at $19 \mathrm{~h} \mathrm{32m}$ 30s local time and an extremely slow shaking lasted for about 5 $\mathrm{min}$. At $19 \mathrm{~h} 50 \mathrm{~m}$, or $18 \mathrm{~min}$ after the earthquake, the sea began to recede. At about $20 \mathrm{~h}$, the water rose, but fell somewhat in a few minutes. At $20 \mathrm{~h} 07 \mathrm{~m}, 35 \mathrm{~min}$ from the earthquake, the largest tsunami of about $4.5 \mathrm{~m}$ high arrived and instantly swept away all houses and people. Although the absolute timing of this observation may not be accurate, the relative timing between the ground shaking and tsunami arrivals is important.

The tsunami was also recorded on several tide gauges in Japan and the U.S. [e.g., Imamura and Moriya, 1939]. We used the tsunami waveforms recorded at three tide gauge stations in Japan: Hanasaki, Ayukawa, and Choshi (see Fig. 3). Omori [1902] carefully examined the seismic and tide gauge records. He applied a clock correction to the Choshi record and mentioned that the clock correction was unnecessary for the Ayukawa record. However, considering the poor accuracy of clocks in those days, the error does not seem to be smaller than $5 \mathrm{~min}$. Previous estimates of the tsunami source area using an inverse refraction method [e.g., Hatori, 1974] have not considered the clock accuracy. In this study, after examining the system and accuracy of clocks, we decided to use the waveforms only without absolute timing. On the other hand, the travel times to Miyako may be reliable, because they are the travel time difference between the seismic and tsunami waves.

The tsunami waveforms are numerically computed on actual bathymetry. Finite difference computations of the linear long wave equation [e.g., Satake, 1995] are carried out on a grid system with an interval of 1 minute of the arc. The time step of
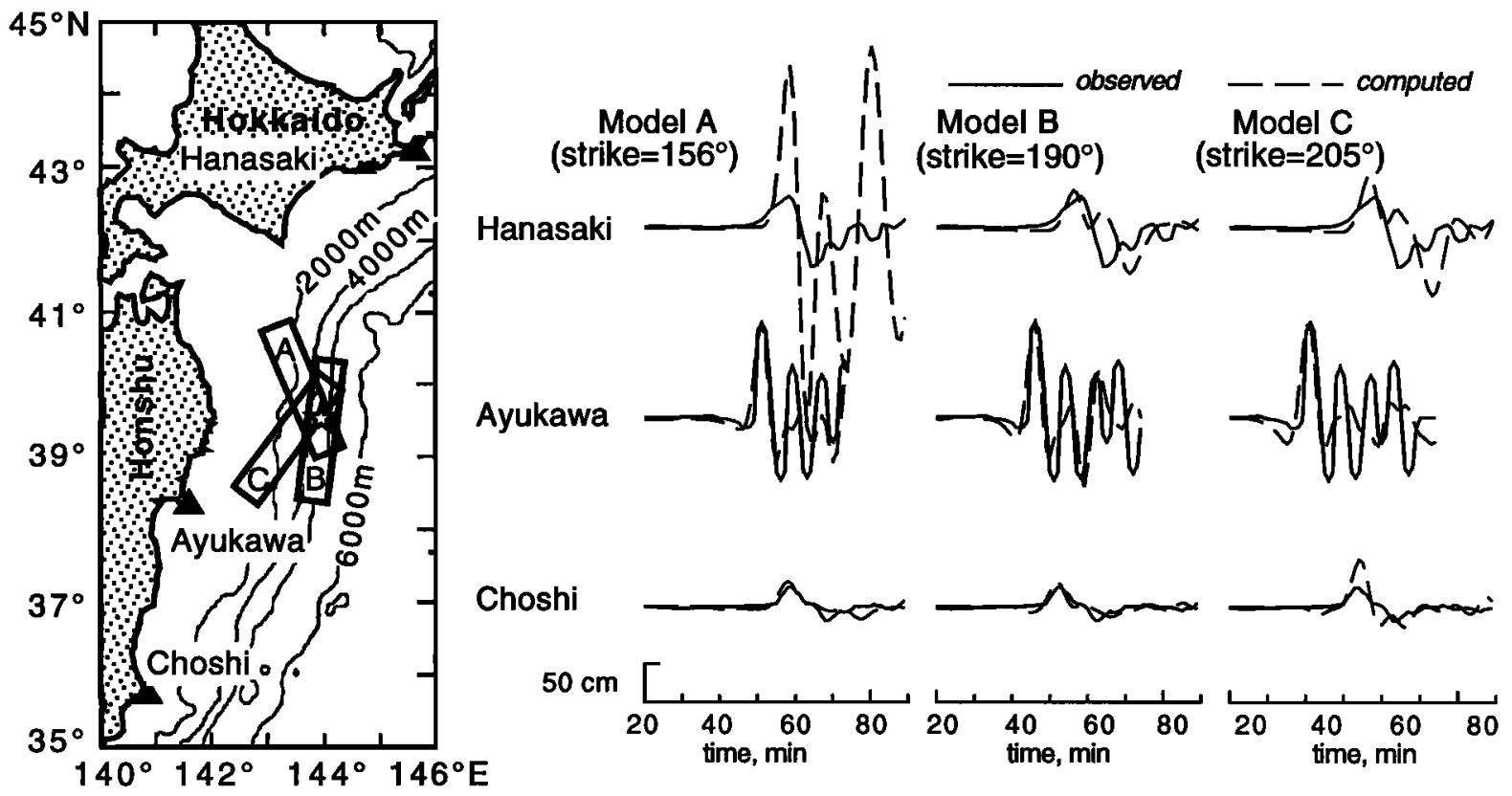

Figure 3. Comparison of the observed (solid curves) and computed (dashed) tsunami waveforms from three fault models with different strikes as shown in the left map. The open star is the epicenter of the 1896 earthquake. The solid triangles indicate the tide gauge locations. 
computation is $3 \mathrm{~s}$ to satisfy the stability condition. The initial condition of the tsunami propagation is calculated from the vertical and horizontal displacements of the ocean bottom [Tanioka and Satake, 1996], which are computed using Okada's [1985] equations.

We attempt to estimate the fault strike, width, and location; these are important parameters to understand this unusual tsunami earthquake. From the three tsunami waveforms without absolute time, it may be difficult to estimate the other fault parameters.

\section{Fault Strike}

We first computed tsunami waveforms from three fault models with different strikes as shown in Fig. 3. Model A is Aida's [1977] fault model (strike $156^{\circ}$, dip angle $20^{\circ}$ and slip direction $280^{\circ}$ ), having the same strike as the 1968 Tokachi-oki earthquake, which occurred about $120 \mathrm{~km}$ north of the 1896 event. The length and width of the fault are $210 \mathrm{~km}$ and $50 \mathrm{~km}$, respectively. Model B has a strike parallel to the Japan trench $\left(190^{\circ}\right)$. The other parameters are the same as in Model A. Model C has a strike of $205^{\circ}$, the same as Aida's [1977] model for the 1897 Sanriku earthquake, which occurred about $100 \mathrm{~km}$ south of the 1896 epicenter. The slip direction is kept constant at ${\mathrm{N} 80^{\circ} \mathrm{W}}^{\circ}$ [Aida, 1977] for the three models, so that the rake angles are different. Because the relative plate motion on the Japan trench is about $\mathrm{N} 64^{\circ}-68^{\circ} \mathrm{W}$, we also computed tsunami waveforms from the slip direction of $\mathrm{N}^{\circ} 5^{\circ} \mathrm{W}$, but the waveforms at the three tide gauge stations and at Miyako were almost identical to those from $\mathrm{N} 80^{\circ} \mathrm{W}$.

Comparison of the observed and synthetic tsunami waveforms (Fig. 3) indicates that Model B is the closest to the observed waveforms. In Fig. 3, the first arrivals for all the stations are adjusted to match. The amplitudes of synthetics are normalized to the amplitude of the first crest at Ayukawa for each model. Model A (Aida's fault parameters) produces a much larger amplitude than that observed at Hanasaki. The computed tsunami at Choshi from Model $\mathrm{C}$ is also larger than the observed. These amplitude differences are due to the directivity effect; the tsunami waves emitted in the direction perpendicular to the fault strike become large. The best model is clearly Model B, which has a strike parallel to the Japan trench.

\section{Fault Width}

We next computed tsunami waveforms from different fault widths, $30 \mathrm{~km}, 50 \mathrm{~km}$ and $100 \mathrm{~km}$, and compared them with the observations (Fig. 4). The other parameters are the same as in

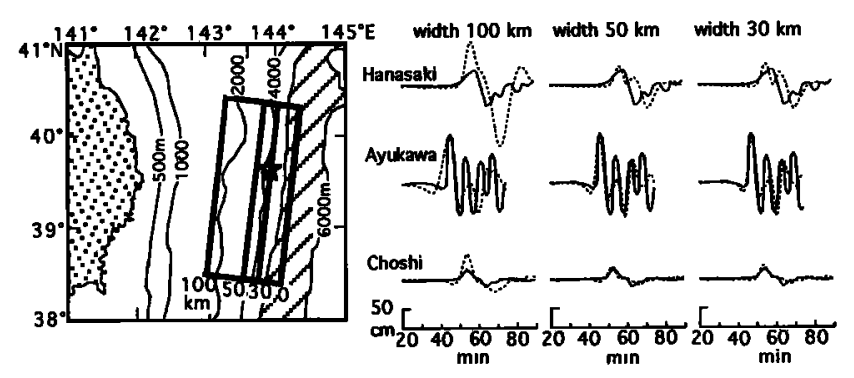

Figure 4. Comparison of the observed (solid curves) and computed (dashed) waveforms from different fault widths (100 $\mathrm{km}, 50 \mathrm{~km}$ and $30 \mathrm{~km}$ ). The locations of the three models are shown in the left panel.
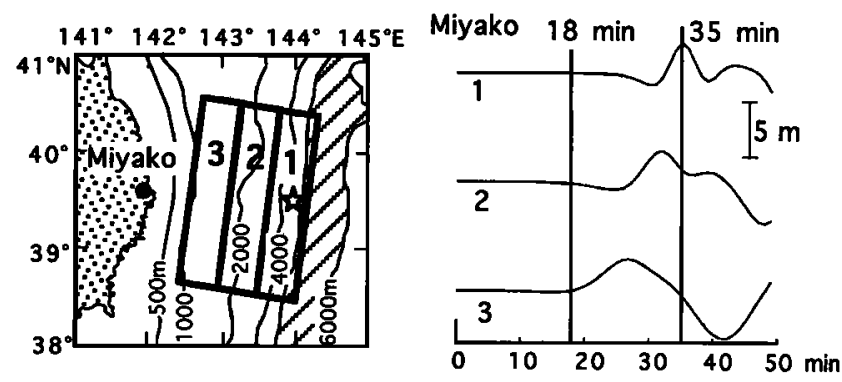

Figure 5. Comparison of the computed tsunami waveforms at Miyako from three different locations as shown in the left panel. The observed tsunami arrival (18 min with receding motion) and the maximum amplitude ( $4.5 \mathrm{~m}$ at $35 \mathrm{~min}$ ) are shown by vertical lines.

Model B. As before, the first arrivals are adjusted to match at all the stations and the synthetic amplitudes are normalized to the amplitude of the first crest at Ayukawa. The computed amplitude at Hanasaki from the $100 \mathrm{~km}$ wide fault is much larger than the observed. The computed period of the first cycle at Ayukawa is also longer than the observed. The computed tsunamis from narrower faults are closer to the observed waveforms. Hence, we conclude that the fault width is $50 \mathrm{~km}$ or less.

\section{Fault Location}

We then shifted the $50 \mathrm{~km}$ wide fault along the down-dip direction as shown in Fig. 5. The top depth of the fault is 0,16 and $32 \mathrm{~km}$ for locations 1,2 , and 3 , respectively. We computed

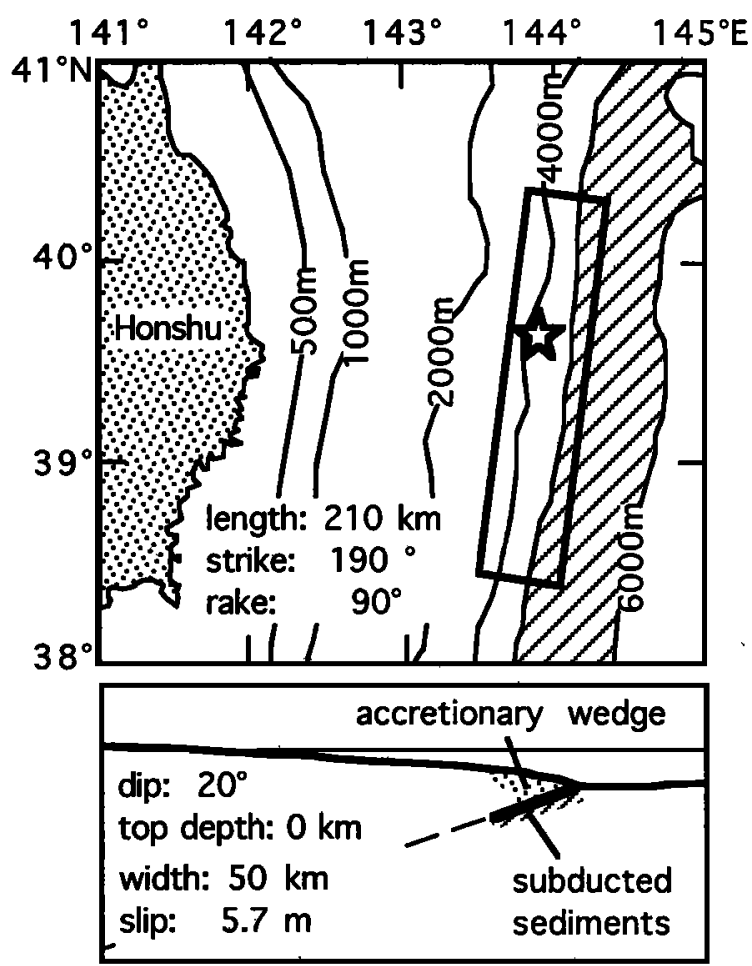

Figure 6. The fault model for the 1896 Sanriku tsunami earthquake. The top is in map view and the bottom is a crosssectional view. The accretionary wedge from Suyehiro and Nishizawa [1994] and the subducted sediments (vertically exaggerated) from von Huene et al. [1994] are shown in the bottom figure. 
tsunami waveforms at Miyako. The travel time at Miyako is sensitive to the fault location because Miyako is located in a direction perpendicular to the fault strike. Although the waveform is not available at this station, the visual observation indicates that the first wave arrived at $18 \mathrm{~min}$ with a downward motion and the maximum amplitude of $4.5 \mathrm{~m}$ appeared at $35 \mathrm{~min}$ after the earthquake, as we already described. Figure 6 shows that only location 1 , the most trenchward location, satisfies these observations. If the fault was located closer to the coast, the maximum amplitude would appear earlier. Hence the location of the fault is confirmed to be near the trench axis, where the ocean depth is about $6000 \mathrm{~m}$.

\section{Discussion and Conclusion}

We have fixed the fault length as $210 \mathrm{~km}$ which was suggested by Aida [1977]. In our modeling, we do not have a constraint on the fault length because we ignored the absolute timing of the tide gauge records. In addition, Aida's [1977] model may have a better constraint on the fault length, because he compared the observed tsunami run-up heights along the Sanriku coast with the computed tsunami amplitudes at $200 \mathrm{~m}$ depth.

The slip amount for our final model is estimated to be $5.7 \mathrm{~m}$ from the amplitude comparison of the observed and computed waveforms. As we have seen already, the slip was concentrated near the trench. If we assume the rigidity around such a shallow fault is $2 \times 10^{10} \mathrm{~N} / \mathrm{m}^{2}$, then the seismic moment is computed to be $12 \times 10^{20} \mathrm{Nm}$, corresponding to $M_{W}=8.0$. This value is close to Utsu's [1994] estimate (8.0-8.2) from the number of aftershocks, but much larger than the surface wave magnitude $\left(M_{S}=7.2\right)$ and still smaller than the tsunami magnitudes $\left(M_{t}=8.2-\right.$ 8.6). The former discrepancy is probably due to a slow and long rupture process of the earthquake as suggested by Kanamori [1972].

We conclude that the strike of the 1896 Sanriku earthquake is parallel to the trench and the large displacement must have occurred in a shallow depth near the trench axis (Fig. 6). Suyehiro and Nishizawa [1994], from their ocean bottom refraction study, indicate that the accretionary wedge near the Japan trench off the Sanriku coast is very small. In this region, the sediments are being subducted and the plate interface is filled with water-bearing sediments as imaged by multichannel seismic data [von Huene and Culotta, 1989; von Huene et al., 1994]. The rupture in such soft sediments would be very slow. The 1896 Sanriku tsunami earthquake is possibly a slow rupture on a shallow fault in the subducted sediments beneath the accretionary wedge, which has been suggested for other tsunami earthquakes [Kanamori and Kikuchi, 1993; Satake, 1994]. Further comparison and tectonic interpretation of the 1896 tsunami earthquake and other types of earthquakes are the subject of another paper [Tanioka et al., 1996b].

Acknowledgments. We thank Yuki Hatanaka at Geographical Survey Institute for information on tide gauge and clock system, Larry Ruff and Debra Tjoa for reading the manuscript and providing us helpful comments. This work was partially supported by NSF (EAR 9405767).

\section{References}

Abe, K., Size of great earthquakes of 1873-1974 inferred from tsunami data, J. Geophys. Res., 84, 1561-1568, 1979.
Abe, K., Physical size of tsunamigenic earthquakes of the northwestern Pacific, Phys. Earth Planet. Inter., 27, 194-205, 1981.

Abe, K., Instrumental magnitudes of historical earthquakes, 1892-1898, Bull. Seism. Soc. Am., 84, 415-425, 1994.

Aida, I., Simulations of large tsunamis occurring in the past off the coast of the Sanriku district, Bull. Earthq. Res. Inst. Univ. Tokyo, 52, 71 101, 1977 (in Japanese).

Fukao, Y., Tsunami earthquakes and subduction processes near deep-sea trenches, J. Geophys. Res., 84, 2303-2314, 1979.

Hatori, T., Tsunami sources on the Pacific side in northeast Japan, Zisin (J. Seism. Soc. Japan) ser. 2, 27, 321-337, 1974 (in Japanese).

Iki, T., Field survey report of the 1896 Sanriku tsunami, Rep. Imp. Earthq. Inv. Comm., 11, 5-34, 1897 (in Japanese).

Imamura, A., and M. Moriya, Mareographic observations of tunamis in Japan during the period from 1894 to 1924, Japan J. Astron. Geophys., 17, 119-140, 1939.

Kanamori, H., Mechanism of tsunami earthquakes, Phys. Earth Planet. Inter., 6, 246-259, 1972.

Kanamori, H., and M. Kikuchi, The 1992 Nicaragua earthquake: a slow tsunami earthquake associated with subducted sediments, Nature, 361, 714-716, 1993.

Okada, Y., Surface deformation due to shear and tensile faults in a halfspace, Bull. Seism. Soc. Am., 75, 1135-1154, 1985.

Okal, E.A., Seismic parameters controlling far-field tsunami amplitudes: a review, Natural Hazards, I, 67-96, 1988.

Omori, F., On tsunami around Japan, Rep. Imp. Earthq. Inv. Comm., 34, $5-79,1902$ (in Japanese).

Omori, F., and K. Hirata, Earthquake measurement at Miyako, J. Sci. Coll. Imp. Univ. Tokyo, 11, 161-195, 1899.

Pelayo, A.M., and D.A. Wiens, Tsunami earthquakes: slow thrustfaulting events in the accretionary wedge, J. Geophys. Res., 97, 1532115337, 1992.

Satake, K., Mechanism of the 1992 Nicaragua tsunami earthquake, Geophys. Res. Lett., 21, 2519-2522, 1994.

Satake, K., Linear and nonlinear computations of the 1992 Nicaragua earthquake tsunami, PAGEOPH, 144, 455-470, 1995.

Suyehiro, K., and A. Nishizawa, Crustal structure and seismicity beneath the forearc off northeastem Japan, J. Geophys. Res., 99, 22331-22347, 1994

Tanioka, Y., and K. Satake, Tsunami generation by horizontal displacement of ocean bottom, Geophys. Res. Lett., 23, 891-894, 1996.

Tanioka, Y., L. Ruff and K. Satake, The Sanriku-oki, Japan, earthquake of December 28, 1994 (Mw 7.7): Rupture of an asperity unbroken in a previous earthquake, Geophys. Res. Lett., in press, 1996a.

Tanioka, Y., L. Ruff, and K. Satake, What controls the lateral variation of large earthquake occurrence along the Japan Trench? The Island Arc, submitted, 1996b.

Utsu, T., Seismicity of Japan from 1885 through 1925, Bull. Earthq. Res. Inst. Univ. Tokyo, 54, 253-308, 1979 (in Japanese).

Utsu, T., Aftershock activity of the 1896 Sanriku earthquake, Zisin (J. Seism. Soc. Japan) ser. 2, 47, 89-92, 1994 (in Japanese).

von Huene, R., and R. Culotta, Tectonic erosion at the front of the Japan Trench convergent margin, Tectonophysics, 160, 75-90, 1989.

von Huene, R., D. Klaeschen, B. Cropp, and J. Miller, Tectonic structure across the accretionary and erosional parts of the Japan Trench margin, J. Geophys. Res., 99, 22349-22361, 1994.

K. Satake, Seismotectonics Section, Geological Survey of Japan, Tsukuba, Ibaraki 305, Japan (e-mail: satake@gsj.go.jp) Y. Tanioka, Dept. of Geological Sciences, Univ. of Michigan, Ann Arbor, MI 48109-1063 (e-mail: tanioka@umich.edu)

(Received April 16, 1996; accepted May 6, 1996.) 